\title{
Effective Power Quality Improvement using Generalised Unified Power Quality Conditioner
}

\author{
K. Bavitra ${ }^{*}$, S. Sinthuja ${ }^{2}$ and N. Manoharan ${ }^{1}$ \\ 'AMET University, India; bavitra720.chm@gmail.com, Directorresearch@ametuniv.ac.in \\ ${ }^{2}$ Tejas Research Centre of Excellence, AMET University, India; sinthuja.engg@gmail.com
}

\begin{abstract}
Generalized Unified Power Quality Conditioner (GUPQC) is used to compensate voltage sag and swell by injecting voltage into the feeder. GUPQC consist of voltage source converters, capacitor, injecting transformers and filters. One voltage source converter is connected in shunt to compensate current harmonics and rests of the converters are connected in series to compensate voltage harmonics and they are connected to a common energy storage device. In this paper capacitor is used as energy storage device. Fuzzy controller and PI controller are used to provide the pulses for voltage source converter to inject the voltage and current into the feeder. Results are verified using MATLAB simulink.
\end{abstract}

Keywords: Capacitor, Generalized Unified Power Quality Conditioner, PI Controller Fuzzy Controller, Unified Power Quality Conditioner, Voltage Sag, Voltage Source Converter, Voltage Swell

\section{Introduction}

Power quality problems are one of the major problems in the distribution side. There are various power quality problems they are voltage sag, voltage swell, harmonics, notching and noise ${ }^{1}$. This power quality problem causes severe problem to the load connected in the distribution side, so these problems have to be compensated in order to protect sensitive loads. There are various custom power devices they are unified power quality conditioner, interline unified power quality conditioner, generalized unified power quality conditioner and few more ${ }^{2}$. This paper describes about generalized unified power quality conditioner. Major blocks included in generalized unified power quality conditioner are voltage source converter, injecting transformer and capacitor, where capacitor is used as the energy storage device. In order to control the power quality and also to provide effective.

Dynamic and steady state voltage control in sub transmission lines voltage source converters are preferred $^{3}$. The distributed generator and its combination with Unified Power Quality Conditioner is analyzed ${ }^{4}$.
$\mathrm{UPQC}$ is a custom power device which also helps to compensate voltage sag and swell. They have a new control strategy in which unbalance load causing distortions are balanced ${ }^{5}$. There is a new proposal of a system which consist of a series voltage source converter, shunt voltage source converter and a generator connected in a DC link so the output from the generator is helpful in charging the capacitor ${ }^{6}$. There are new types of UPQC which consist of three voltage source converter which is very similar to GUPQC by controlling the switching of the switches in voltage source converter. It acts as series and shunt active power filter? The output feedback control of a UPQC is studied and control methods are analyzed ${ }^{8}$. Advancement of UPQC is the interline power quality conditioner which helps to improve the power quality of the feeder. It consists of two voltage source converters connected to a common DC link. One voltage source converter is connected in series and other connected as shunt ${ }^{9}$. Generalized unified power quality conditioner is designed with three voltage source converters for three feeders. Where one is connected in shunt and the rest in series ${ }^{10}$. Power quality can be improved by using a cascade multilevel converter instead

${ }^{*}$ Author for correspondence 
of voltage source converter but due to the limitations in cascade multilevel inverter voltage source inverter is preferred ${ }^{11}$. Controller used in this paper is PI controller and fuzzy controller, which compares the actual voltage with the reference voltage and produce the error signal.

\section{General GUPQC Configuration}

Among various custom power devices used in recent trends, GUPQC is preferred over the other devices to compensate voltage and current harmonics. Figure 1 shows the schematic diagram of GUPQC. It consists of three voltage source converters connected in a manner in which to compensate voltage sag and swell. Sensitive loads are protected from voltage sag and voltage swell, which is caused mainly by addition of load and three phase fault. Three voltage source converters are connected in a manner in which all the three voltage converters share the same energy storage device, which is a capacitor used in this paper.

These voltage source converters inject voltage into the feeder through injecting transformer when there is voltage sag and absorb the voltage sag from feeder when voltage is increased above normal voltage. In order to compensate both voltage and current harmonics one voltage source converter is connected in shunt manner and other voltage source converter are connected in a series manner to the feeder. So shunt connected voltage source converter are operated as a current source converter to compensate current harmonics. Series connected voltage transformer helps to compensate voltage harmonics. Controller is the heart of the GUPQC system which detects voltage sag and voltage swell.

\section{Proposed Model}

Figure 2 shows the basic block diagram proposed in this paper. It consists of three voltage source converters

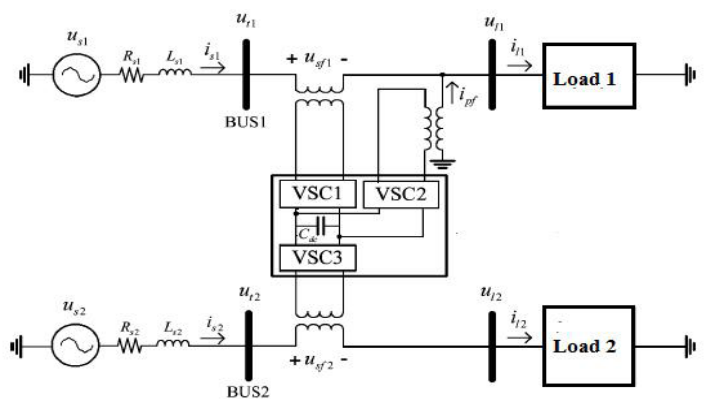

Figure 1. Schematic Diagram of GUPQC.

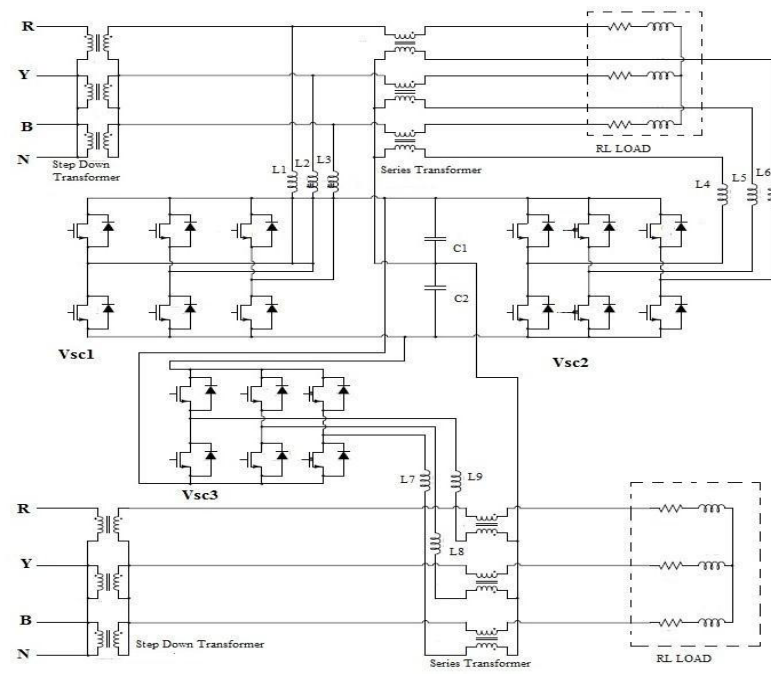

Figure 2. Basic block diagram of GUPQC.

connected back to back, three filters and an energy storage device. This voltage source converter produce three phase output which is injected to the feeder to compensate voltage sag, swell and harmonics which are series connected and the shunt connected.

\subsection{Fuzzy Controller}

Fuzzy logic controller is an attempt to mimic human control logic. This consists of fuzzy code which is designed to control particular part depending upon application. They are advantageous over other controllers because they are robust and can be easily modified. They can also have multiple inputs and outputs. They have a fuzzification block followed by a rule base and decision making unit then a defuzzification interface. The inputs are fuzzified in fuzzification block. Rule base provide basic knowledge of the system and decision making block is helpful in deciding which operation to be performed in GUPQC. It includes whether the voltage has to be injected or absorbed. Defuzification block defuzzify the output. Figure 3 shows the basic block diagram for the fuzzy logic controller. This fuzzy logic controller produce error signals which is required for the PWM generator to produce pulses for Switches used.

\subsection{PI Controller}

In this paper, PI controller is compared with fuzzy controller and PI controller is generally a PID controller and generic control feedback mechanism. Where PID controller composed of proportional part, integrated part 


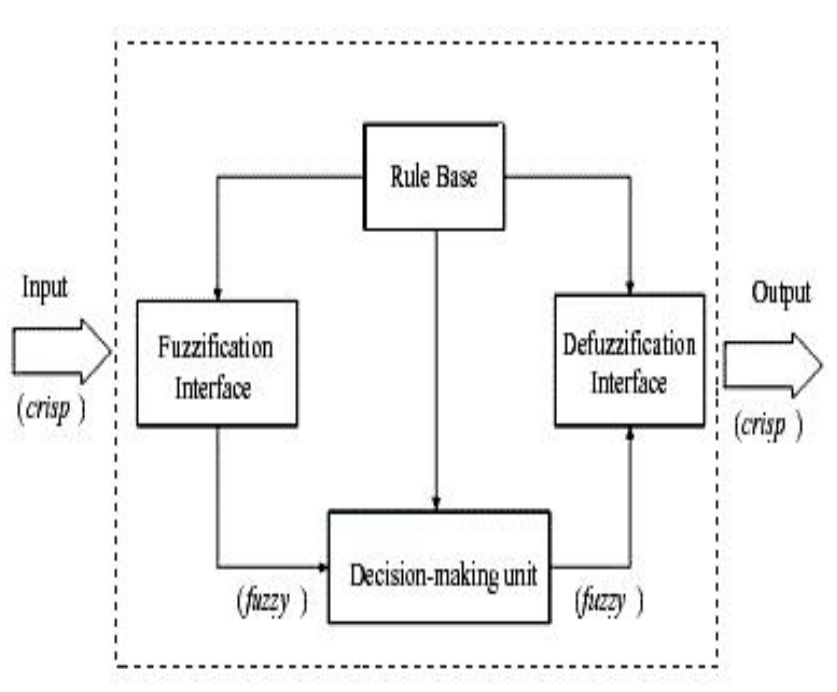

Figure 3. Basic block diagram of Fuzzy controller.

and derivative part. Derivative part is very sensitive which means that it is very prone to noises. But usually there will be some tolerable noises in the system. When a controller reacts to such noises it causes the system to be unstable which can be avoided using PI controller. PI controller is is less responsive to real (non-noise) and relatively fast alterations in state and so the system will be slower to reach set point and slower to respond to perturbations. This controller also compares reference voltage with the actual voltage and produce error signal. This error signal is responsible for the generation of pulses required for the voltage source converter. Figure 4 shows the basic block diagram of PI controller.

\subsection{Voltage Source Converter}

Voltage source converter is a device which converter DC signals in to AC signal. In a three phase application the produce three phase signals. It consists of six switches

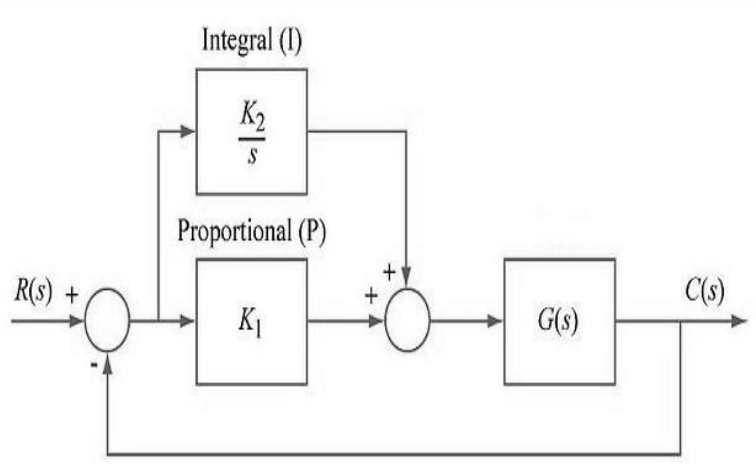

Figure 4. Basic block diagram of PI controller. operated in a sequence to produce three phase voltage waveform. In this paper, three voltage source converters are used. They are connected back to back through a capacitor. These switches are given pulses from pulse generator. Due to the advantages of voltage source converter over current source converter, voltage source converter is preferred. Turning the switches on and off is controlled by the PWM generator which is controlled by controller. Proper switching provides appropriate magnitude of voltage to get injected into the feeder. Figure 5 shows basic diagram for voltage source converter.

\subsection{Filters}

Output from the voltage source converter contains harmonics. This harmonics can be eliminated by using filters in series with the output from the voltage source converter. Filters are a combination of inductor and capacitor connected in such a way to compensate the harmonics.

\subsection{Injecting Transformer}

There are three injecting transformers used. These injecting transformers isolate the high voltage side feeder from the voltage source converters.

\subsection{Load}

Load used in this paper is linear load which is a RL load addition of RL load causes voltage sag and addition of energising load causes voltage swell. Due to the presence of power electronic switches they provide some harmonics in the supply voltage.

\subsection{Transformation Used}

The $\mathrm{p}-\mathrm{q}$ theory implements a transformation from a stationary reference system in $\mathrm{a}-\mathrm{b}-\mathrm{c}$ coordinates, to a

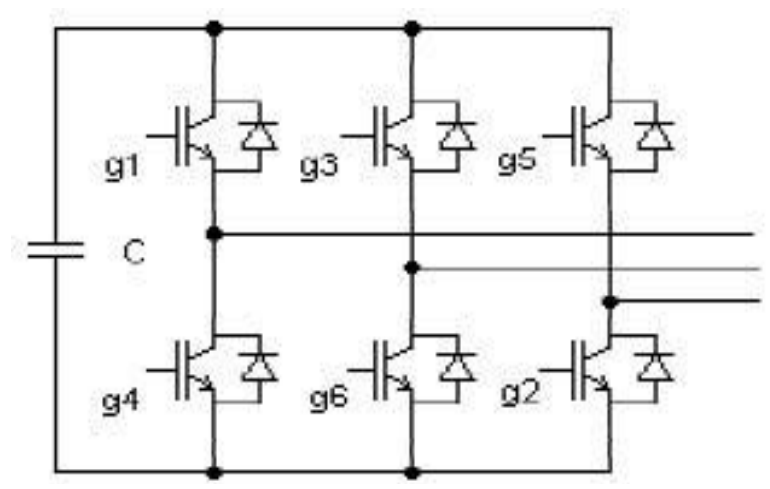

Figure 5. Voltage source converter. 
system with coordinate's $\alpha-\beta-0$. It corresponds to an algebraic transformation, known as Clarke transformation, which also produces a stationary reference system, where coordinates $\alpha-\beta$ are orthogonal to each other, and coordinate 0 corresponds to the zero-sequence component. The equation related to $\mathrm{p}-\mathrm{q}$ transformation is shown below.

$$
\left[\begin{array}{c}
V_{0} \\
V_{\alpha} \\
V_{\beta}
\end{array}\right]=\sqrt{\frac{2}{3}}\left[\begin{array}{ccc}
1 \sqrt{2} & 1 \sqrt{2} & 1 \sqrt{2} \\
1 & -1 / 2 & -1 / 2 \\
0 & \sqrt{3} / 2 & -\sqrt{3} / 2
\end{array}\right] \times\left[\begin{array}{c}
V_{a} \\
V_{b} \\
V_{c}
\end{array}\right]
$$

\section{Simulation Results}

A three phase supply voltage of $415 \mathrm{~V}$ is supplied to the sensitive load. Due to the presence of three phase fault, voltage sag is created. Three phase fault is turned on during the time period of $0.15 \mathrm{~S}$ to $0.25 \mathrm{~S}$. Voltage sag causes so many problems and causes the load to get damaged. So in order to avoid damages in the sensitive load, GUPQC is activated during the interval when voltage sag is detected. This is done by the fuzzy controller. This voltage sag is compensated due to the presence of GUPQC. Figure 6 shows the simulation result for voltage sag compensation.

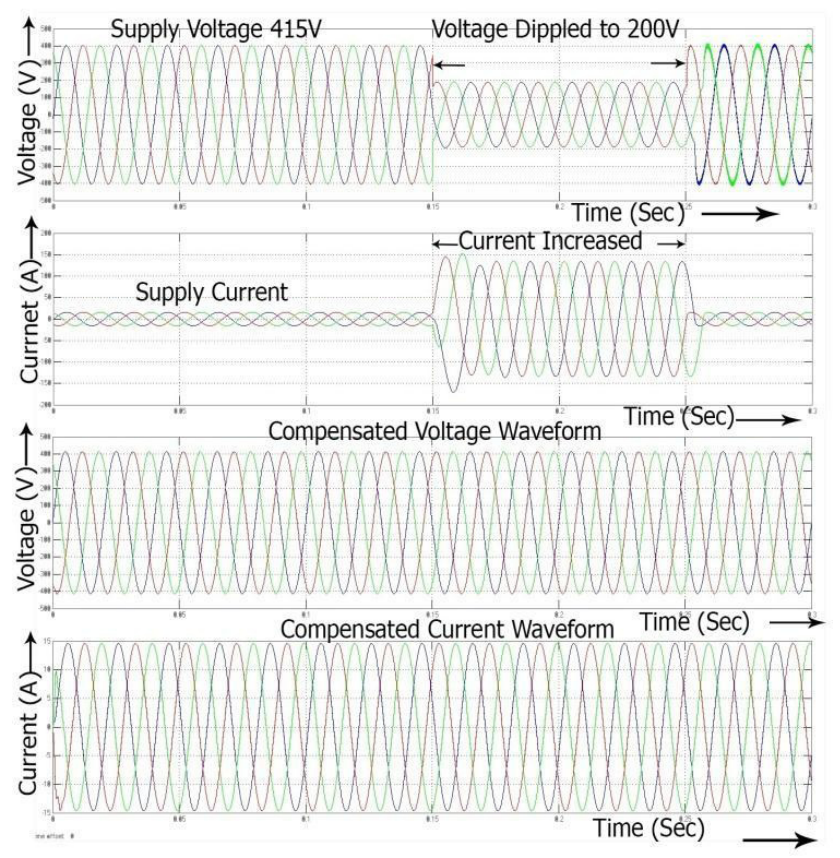

Figure 6. Simulation result for voltage sag compensation by fuzzy controller.
A three phase voltage supply of $415 \mathrm{~V}$ is increased to $450 \mathrm{~V}$ due to the switching off of the load between the intervals $0.15 \mathrm{~S}$ to $0.25 \mathrm{~S}$. This voltage can be compensated by absorbing the excess voltage which is used to charge capacitor. Fuzzy controller helps to turn the voltage source converter to be turned on between the interval $0.15 \mathrm{~S}$ to $0.25 \mathrm{~S}$ and during the rest of the period the voltage source converter is inactive and it neither absorb nor inject the voltage in or out from the feeder. This sensing of voltage swell duration is done by the fuzzy controller. Figure 7 shows the simulation result for compensating voltage swell. Voltage swell is the major cause for the load to get damaged. When a load is supplied to a voltage higher than the rated voltage and current it causes device

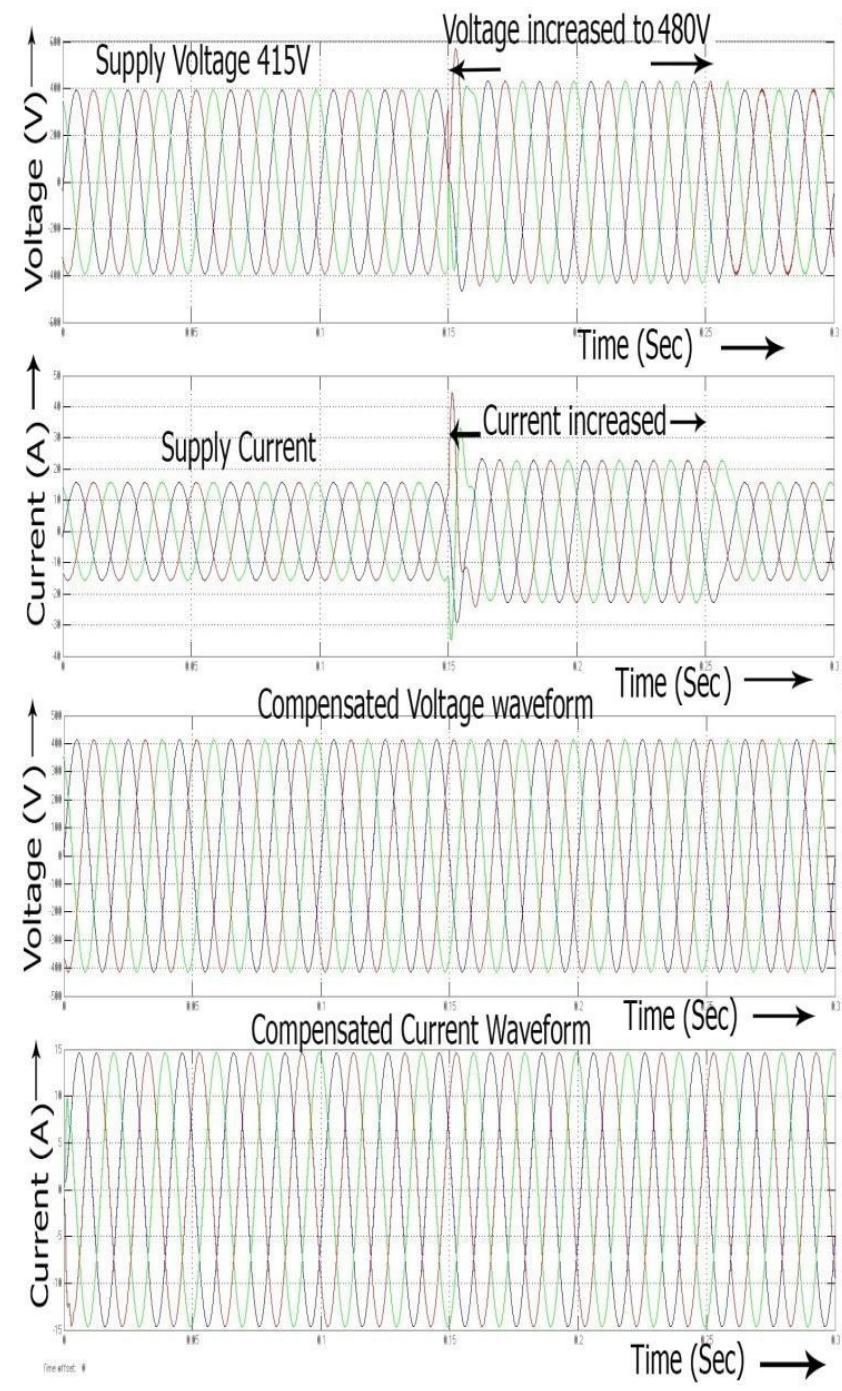

Figure 7. Simulation results for voltage swell compensation by fuzzy controller. 
to get damaged completely and that may cause severe loss economically.

Due to the addition of load in the system voltage and current gets distorted. This distortion causes both loads to get damaged and causes severe loss to the consumer. Load is added during the interval of $0.15 \mathrm{~S}$ to $0.25 \mathrm{~S}$ and GUPQC is activated during the same interval and remain inactive in the rest of the interval. Voltage is injected into the feeder. This causes the voltage to get compensated fuzzy controller is used to control the time period when the voltage source converter needs to be turned on and when it should be turned off. When comparing with the other controller used fuzzy logic controller is used because THD value obtained will be low when compared with other converter. Figure 8 shows the simulation result for compensating voltage due to addition of load.

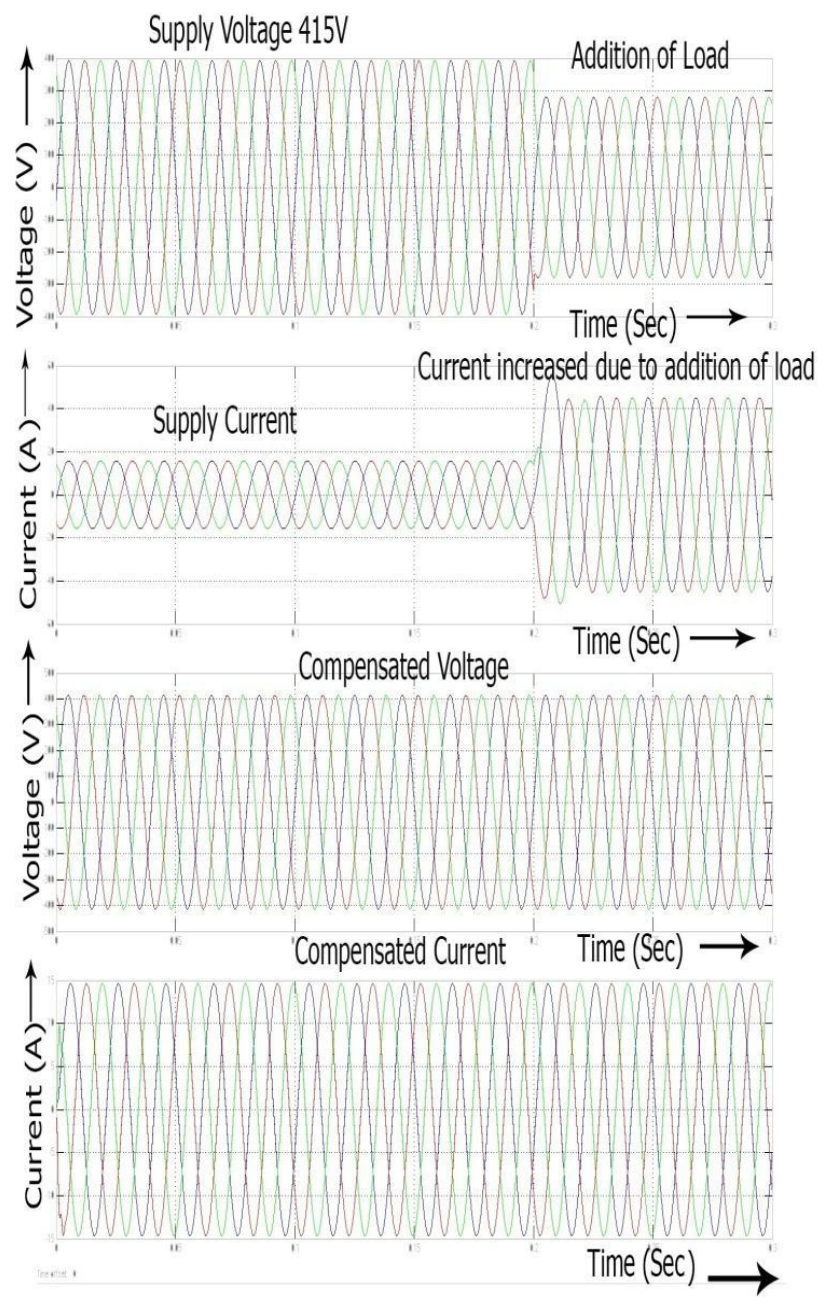

Figure 8. Compensation of voltage sag which is caused due to addition of load by fuzzy controller.
A three phase voltage supply of $415 \mathrm{~V}$ is reduced to $200 \mathrm{~V}$ due to the three phase between the interval $0.15 \mathrm{~S}$ to $0.25 \mathrm{~S}$. This voltage can be compensated by absorbing the excess voltage which is used to charge capacitor. PI controller helps to turn the voltage source converter on between the interval $0.15 \mathrm{~S}$ to $0.25 \mathrm{~S}$ and during the rest of the period the voltage source converter is inactive and it neither absorb nor inject the voltage in or out from the feeder. This sensing of voltage swell duration is done by the pi controller. Figure 9 shows the simulation result for compensating voltage sag. Voltage sag is one of the causes for the load to get damaged. When a load is supplied to a voltage lesser than the rated voltage and current it causes device to get damaged completely and that may cause severe loss economically.

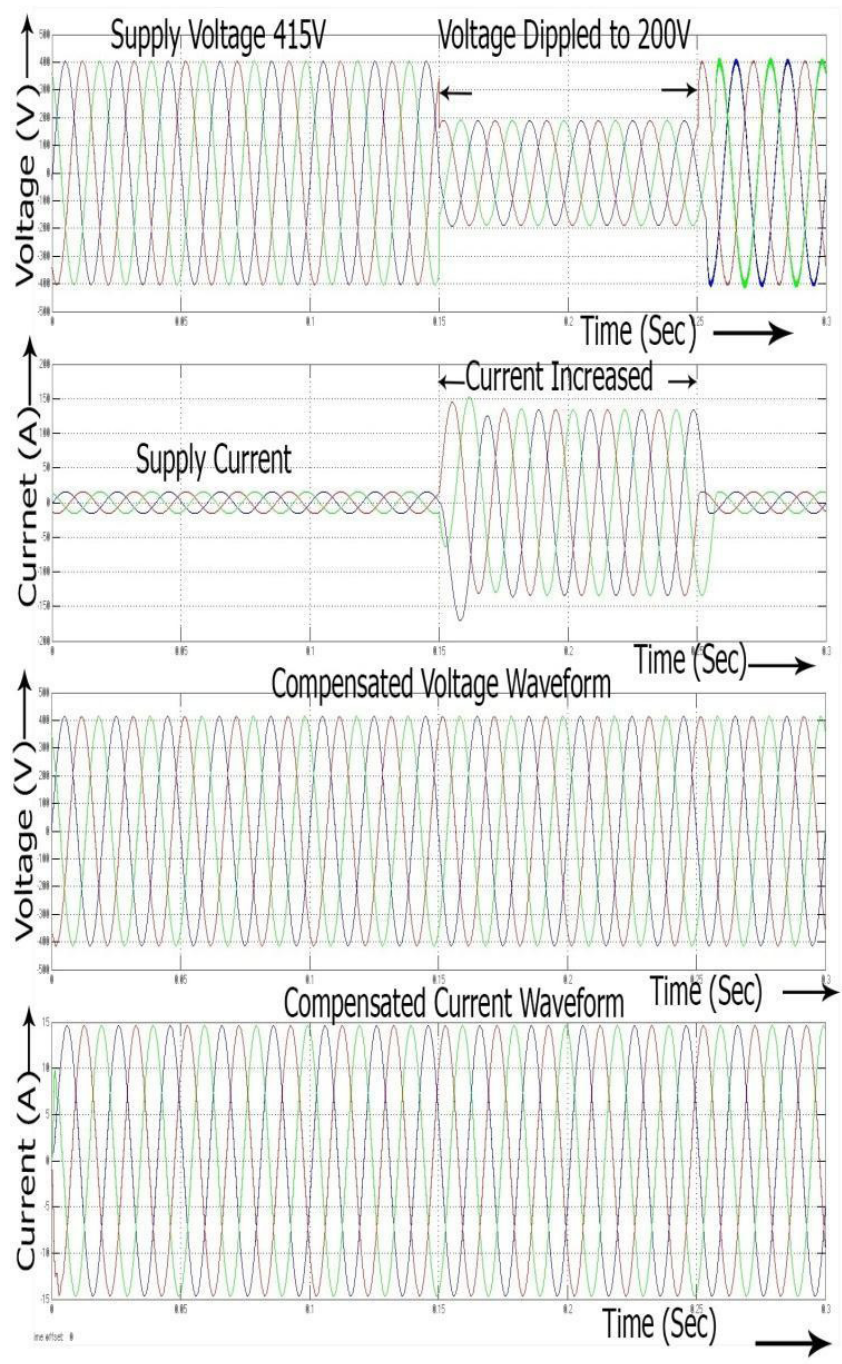

Figure 9. Compensation of voltage sag due to the three phase fault by PI controller. 
A three phase voltage supply of $415 \mathrm{~V}$ is increased to $450 \mathrm{~V}$ due switching of load between the interval $0.15 \mathrm{~S}$ to $0.25 \mathrm{~S}$. This voltage can be compensated by absorbing the excess voltage which is used to charge capacitor. PI controller helps to turn the voltage source converter on between the interval $0.15 \mathrm{~S}$ to $0.25 \mathrm{~S}$ and during the rest of the period the voltage source converter is inactive and it neither absorb nor inject the voltage in or out from the feeder. This sensing of voltage swell duration is done by the PI controller. Figure 10 shows the simulation result for compensating voltage swell. Voltage swell is the major cause for the load to get damaged. When a load is supplied to a voltage higher than the rated voltage and current it causes device to get damaged completely and that may cause severe loss economically.

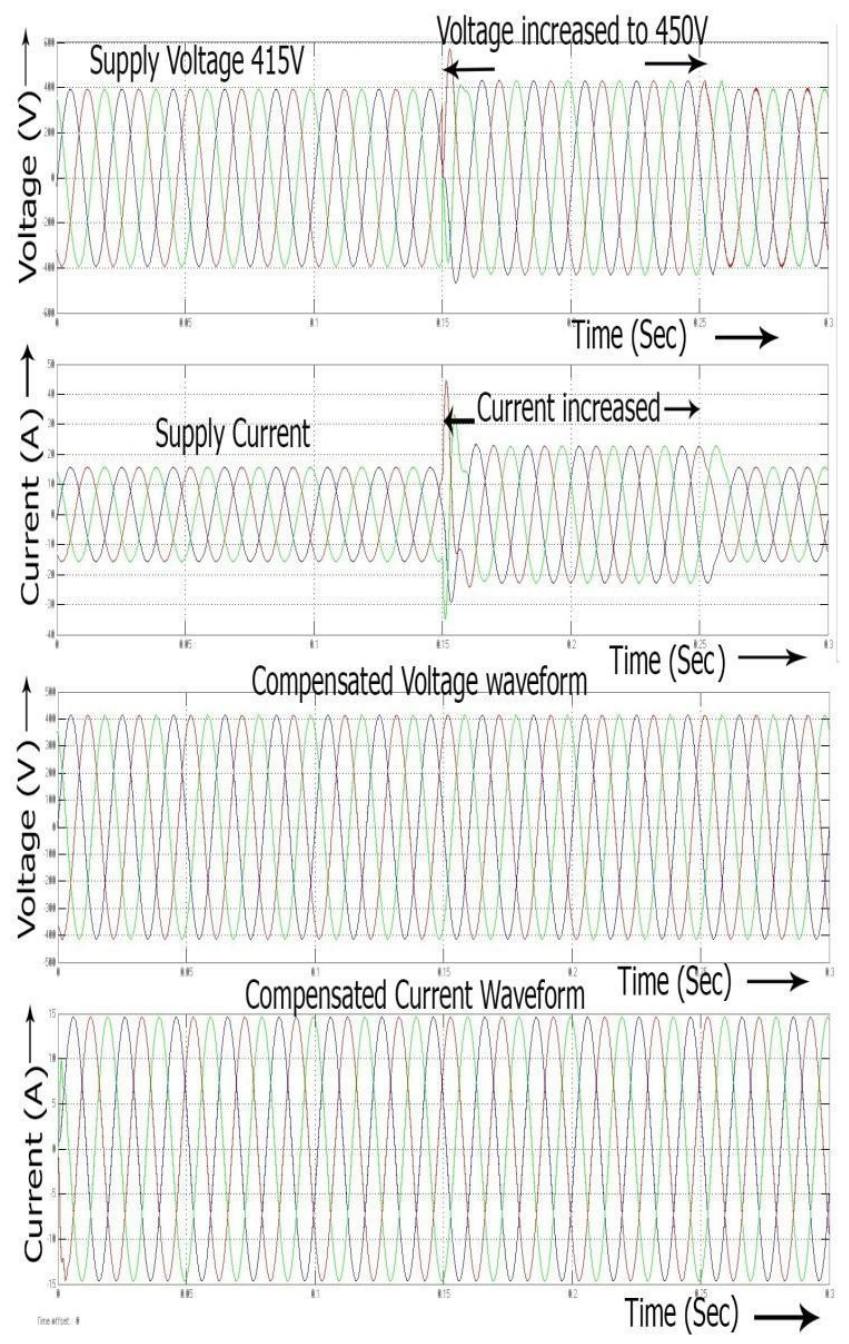

Figure 10. Simulation results for voltage swell compensation by PI controller.
Due to the addition of load in the system voltage and current gets distorted to a voltage of $350 \mathrm{~V}$ and current is increased to 38A. This distortion causes both loads to get damaged and causes severe loss to the consumer. Load is added during the interval of $0.15 \mathrm{~S}$ to $0.3 \mathrm{~S}$ and GUPQC is activated during the same interval and remain inactive in the rest of the interval. Voltage is injected into the feeder. This causes the voltage to get compensated. PI controller is used to control the time period when the voltage source converter needs to be turned on and when it should be turned off. When comparing with the PI controller, fuzzy logic controller is used because THD value obtained will be low when compared with other converter. Figure 11 shows the simulation result for compensating voltage due to addition of load.

Percentage error during voltage compensation when we use PI controller is $2.27 \%$ but percentage error is $0.85 \%$ when we use fuzzy controller. Hence comparing the PI

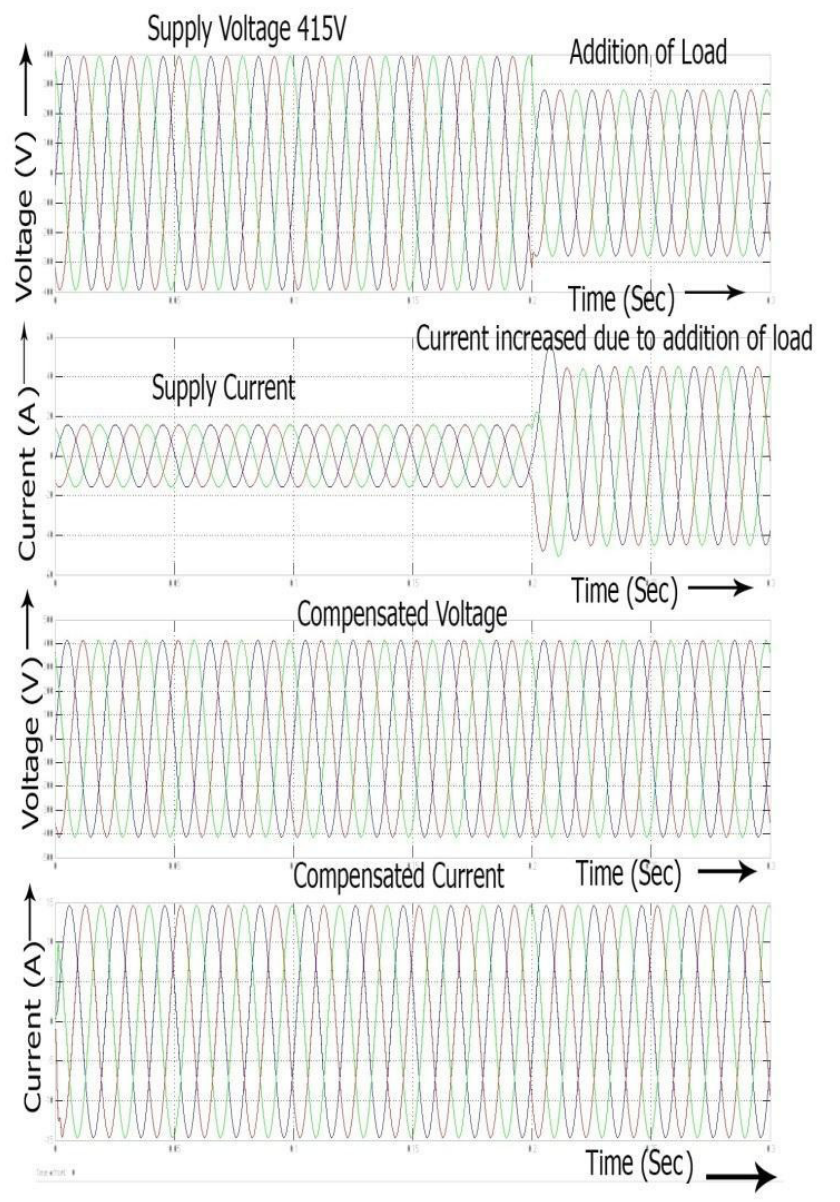

Figure 11. Voltage Compensation due to addition of load by using pi controller. 
controller with the fuzzy controller in this paper, fuzzy controller is more advantageous over PI controller.

\section{Conclusion}

In this proposed model, voltage sag, voltage swell due to addition of load is compensated using GUPQC. Voltage is decreased to $200 \mathrm{~V}$ due to 3 phase fault. This voltage sag is compensated to $415 \mathrm{~V}$ which is the supply voltage. Due to the addition of energizing load, voltage is increased to $480 \mathrm{~V}$ and it is compensated using GUPQC to a normal $415 \mathrm{~V}$. Voltage is compensated using fuzzy logic controller and pi controller, and this controllers are compared and made into a conclusion that fuzzy has advantage over pi controller in this paper.

\section{References}

1. Jindal AK, Ghosh A, Joshi A. Interline unified power quality conditioner. IEEE Transactions on Power Delivery. 2007; 22:364-72.

2. Eldin SMB, Rao KSR, Perumal N. Three-level converters based generalized unified power quality conditioner. Int J Electron Electr Eng. 2012 Apr; 6:167-72.

3. Khadkikar V, Chandra A. A novel structure for three-phase four wire distribution system utilizing unified power quality conditioner. IEEE Transactions on Industry Application. 2009 Sep/Oct; 45(5):1897-902.
4. Hen B, Bae B, Ki H. Combination of unified power-quality conditioner with distributed generation. IEEE Transactions on Power Delivery. 2006 Jan; 21(1):330-8.

5. Fardanesh B, Shperling B, Uzunovic E, Zelingher S. Multiconverter FACTS devices: The generalized unified power flowcontroller. IEEE on Power Engineering Summer Meeting; 2000. p. 2511.

6. Han B, Bae B, Baek S, Jang G. New configuration of UPQC for medium-voltage application. IEEE Transactions on Power Delivery. 2006 Jul; 21(3):1438-44.

7. Mohammadi HR, Varjani AY, Mokhtari H. Multiconverter unified power quality conditioner system MC UPQC. IEEE Transactions on Power Delivery. 2009 Jul; 24(3):1679-86.

8. Rong Y, Li C, Tang H, Zheng X. Output feedback control of single-phase UPQC based on a novel model. IEEE Transactions on Power Delivery. 2009 Jul; 24(3):1586-97.

9. Kesler M, Ozdemir E. Synchronous reference frame based control method for UPQC under unbalanced and distorted load conditions. IEEE Transactions on Industrial Electronics. 2010 Sep; 58(9):3967-75.

10. Khadkikar V, Agarwal P, Chandra A, Barry AO, Nguyen TD. A simple new control technique for Unified Power Quality Conditioner (UPQC). 11th International Conferences on Harmonics and Quality of Power; 2004. p. 289-93.

11. Fujita $H$, Akagi $H$. The unified power quality conditioner: the integration of series and shunt-activefilters. IEEE Transactions on Power Electronics. 1998 Mar; 13(2):315-22. 